EPJ Web of Conferences 110,01024 (2016)

DOI: $10.1051 /$ epjconf/201611001024

(C) Owned by the authors, published by EDP Sciences, 2016

\title{
THE REVIEW OF IGNITION AND COMBUSTION PROCESSES FOR WATER-COAL FUELS
}

\author{
R.I. legorov ${ }^{1}$, P.A. Strizhak ${ }^{1,}$ a, M.Yu. Chernetskiy ${ }^{2}$ \\ ${ }^{1}$ National Research Tomsk Polytechnic University, 634050 Tomsk, Russia \\ ${ }^{2}$ The Institute of Thermophysics of Siberian branch of Russian Academy of Sciences 630090, Novosibirsk, Russia
}

\begin{abstract}
In this work we have reviewed the most of known investigations of the initialization of combustion processes of water-coal fuels. The main problems of such study were emphasized. The definitive effects and factors (like mixing ratio, milling quality, the temperature of the oxidant, properties of the components and methods of the slurry preparation etc.) which have strong influence on inertia and stability of the ignition were analyzed.
\end{abstract}

\section{Introduction}

The water-coal fuel (WCF) is a highly dispersed system (water, milled coal and chemical dopants) which usually has different type of coal as combustible base. The usage of the WCF instead of oilbased fuels became very popular in China, Japan, Sweden, Germany, USA and some other countries during the "energy crisis" at the end of 70-s of previous century. Nowadays the investigations of WCF are very popular in China and Japan. The most famous among related Chinese scientific centers is Governmental Center of Water-Coal Technologies of China. At 2006 China produce and utilize near 15 million tons of WCF per year (enough to produce 10-12GW of electricity), whereas at 2001 they have produced just a bit more than 2 million tons of WCF. Regarding to existing plans, the production of the WCF in China will grow up to 100 million tons per year at 2020 [1]. The significance of the WCF technologies development is highlighted by big amount of Chinese scientific papers devoted to investigations of WCF usage (for example, see [2-9]).

Japan has switched from demo projects of 80 -s to industrial usage of the WCF now, using significant basics of creation and usage of the water-coal fuels [10-15]. They mostly use steam-boilers with power 20-600MW. Approximately 800.000 tons of WCF per year was utilized there during last years. However the water-coal compositions are mostly imported from China and just small part was produced at own production units (using traditional cavitation technology of highly concentrated slurry production).

The first activity about creation of the water-coal technologies in Russia was appeared at 50-s of previous century. At the USSR it was initiated by the growing problem of utilization of fine coal sludges that massively appeared at the time of intensive development of hydraulic mining and hydraulic transportation of the coal as well as at enrichment of coal by "wet" methods. The leading research institutions of the USSR (NPO Gidrotruboprovod, VNIIgidrougol', ИГИ, IFC AC USSR etc.) were invited to solve this problem. The second wave of the scientific investigations related to

a Corresponding author: pavelspa@tpu.ru 
WCF was started at 70-s of previous century after the visit of soviet government delegation to Italy. Active investigations of creation and combustion of the WCF were conducted there. The experimental industrial pipe-transportation system (Belovo-Novosibirsk, the length is $262 \mathrm{~km}$ and the total performance is 3 million tons per year) for water-coal mixture was built at 1989 with participation of Italian company "Snamprogetti". The pipe-transportation system was designed for transportation of the WCF with coal content fraction $\sim 62 \%$. Approximately $350.000 \mathrm{~m}^{3}$ of WCF was delivered to Novosibirsk TEP-5 during the time from 1989 to 1997. Unfortunately, due to some external reasons the pipe-transportation system was stopped at 1997 during the maintain works at Novosibirsk TEP-5 and this industrial experiment was not totally finished.

At the end of XX century the basic data about combustion of the WCF were obtained and at the same time the effective technologies of preparation and usage of water-coal slurries were created [1726]. However, taking in account the real needs in usage of WCF, some countries with deficit of natural resources support research and development activities for improvement of water-coal technologies [2-15]. As result, the systematization of any data about ignition and combustion processes is still of interest.

\section{The main achievements of the last years}

The processes of combustion of water-coal fuels are multi-stage by the nature and actually reproduce the similar processes at combustion of traditional liquid fuels or coal particles (burned in the pulverized state). Together with this there are some principal differences present. In particular, the main differences between ignition and combustion of water-coal slurry droplet and pulverized solid or liquid fuels are following [27]: low-temperature activation of the reaction surface at the ignition stage; growth of the specific reaction surface at the main combustion zone; the intensification of the combustion due to the reaction of carbon with steam, which goes in parallel to the main oxidation reaction.

Experimental [27-29] and theoretical [30-32] investigations allows to distinguish the typical stages of the WCF droplets combustion: the inactive heating; the evaporation of water from the droplet; exiting and combustion of the volatiles that presents inside coal; the burning of the carbon. The last stage takes longest time and it can be up to $90 \%$ of total droplet life-time [32]. For example, fig. 1 shows the stages of water-coal slurry droplet burning (for different types of coals) which were obtained by high-speed video recording [29].

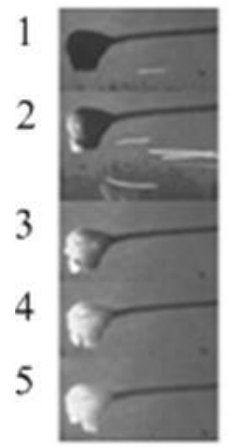

$a$

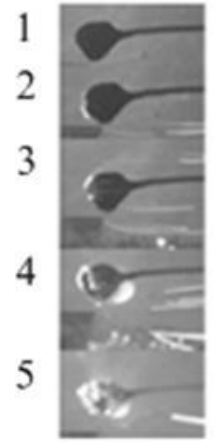

$b$

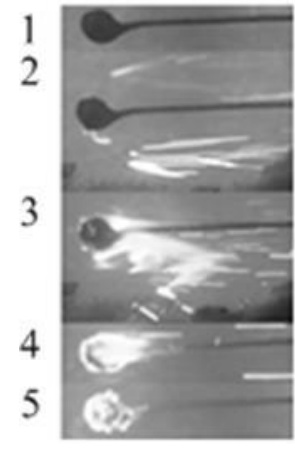

$c$

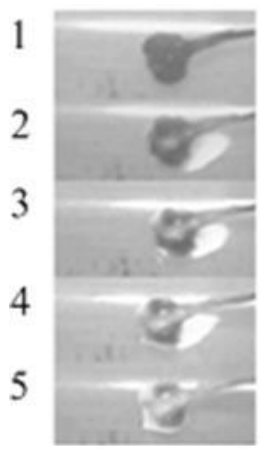

$d$

Figure 1. Typical stages of the droplets burning [29]: $a$ - anthracite-based WCF with average particle size 171 mkm; $b$ - lignite-based WCF with average particle size $145 \mathrm{mkm} ; c$-coal-based WCF with average particle size $135 \mathrm{mkm} ; d$-mixed lignite-coal-based WCF with average particle size $125 \mathrm{mkm}$. 
It was proven [29] that water has evaporated at the first stage (the droplet size does not change a lot). Further, there is heating of the agglomerate with changes of its shape (which is accompanied by corresponding growth of transversal and longitudinal sizes of the droplet). The last stage (combustion of the agglomerate) is characterized by fast (almost exponential) growth of the droplet temperature. Thus the open fire was not registered for anthracite that contains relatively small amount of volatiles in contradistinction to the case for slurries that has coals with enough high amounts of volatiles.

It was shown [29], that delay times of the agglomerate ignition grows non-linearly and the maximal temperature of combustion decreases with growth of water content in slurry.

At present time we can pick out enough large set of the theoretical and experimental works that was done to investigate the processes of creation and utilization of the WCF. Mostly it is oriented to study the influence of the component ratio of slurries, the parameters of the combustion chambers, properties of an oxidant on the conditions and characteristics of stable combustion of the WCF. The corresponding physical and mathematical models were built using the mentioned experimental data.

\subsection{The influence of coal/water ratio onto the characteristics of processes of ignition and combustion of the WCF.}

One of the fundamental problems of modern technologies of water-coal fuel usage is the choice of the actual concentrations of the main components. It has to support the stability of the fuel compositions, their manufacturability, fuel processing, enough high combustion efficiency, stable ignition, minimal transportation costs and costs of the storage. The "water/coal" ratio affects both the structure of the WCF (fig. 2) and its reaction characteristics [29].

At fig. 2 one can see that water-coal slurry becomes less uniform with growth of water fraction amount. This finally affects onto the process of its combustion. The growth of ignition delay and the decrease of the ignition temperature of the fuel (that lead to sharp growth of the temperature curve at fig.2b) were designated [29] by the investigations of the influence of water content in coal-based slurry.

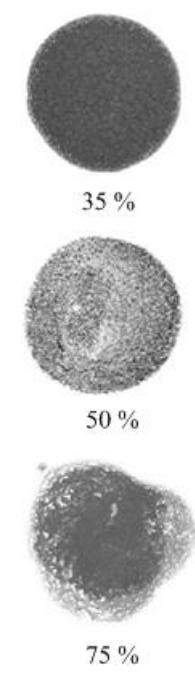

a

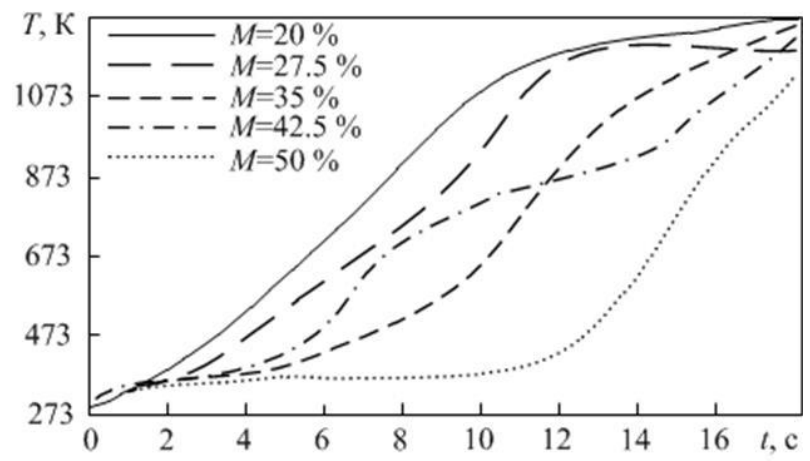

$\sigma$

Figure 2.The images (a) of droplets of the WCF with different water fraction $(35 \%, 50 \%$ and $75 \%)$ with average size of coal particles near $26 \mathrm{mkm}$; The influence (b) of the water fraction of the slurry (that made of the coal) onto the ignition process characteristics [29]. 
The results of the investigations of combustion speed for the extremal cases of "water/coal" ratio ("wet" and preliminary dried "dry" particles of WCF) are shown at [33]. The particle size was changed inside the range $\mathrm{d}=400-2000 \mathrm{mkm}$. The range of changes of the ignition temperature was 870-1670 K. The heating of particles was done by $\mathrm{CO}_{2}$ - laser. The results of the experiments [33] were presented as integral dependence of effective weight speed of combustion of the fuel droplets on heating temperature (Fig. 3).

It was shown [33], that the weight-speed of the droplet combustion is higher at the same temperature of chark residue than for the case of preliminary dried slurry. This fact is defined [33] by thermo-chemical interaction of the chark carbon with steam which leads to creation of low-reactive complexes that accelerate the ignition of the carbon residue.

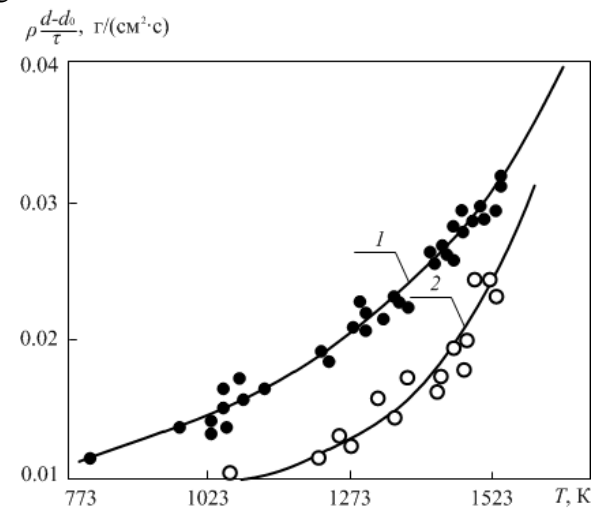

Figure 3. The weight-speed of the slurry droplet combustion (1) and the same for preliminary dried droplet (2): the size of "water-filled" particles $d=400-2000 \mathrm{mkm}$, the size of "dried" particles $\mathrm{d}=68-315 \mathrm{mkm}$ [33].

The theoretical investigations of the integral characteristics of the WCF particles ignition at different concentrations of coal were done in [34]. The conjugation of the main processes of "thermal processing" was taken in account inside the frame of used models of heat-mass-transfer. Models includes passive heating, water evaporation, thermal decomposition of organic components of the fuel, seepage heat and mass transfer, chemical interaction of the chark carbon and steam, the exiting of the combustible volatile components and products of the steam-carbon interaction, their ignition and combustion. The dependencies of the ignition delay $\tau_{\mathrm{d}}$ on concentration (weight fraction) of the coal $\left(\varphi_{4}\right)$ inside the WCF (fig. 4) were obtained in [34] as simulation results for different diameters of fuel particles.

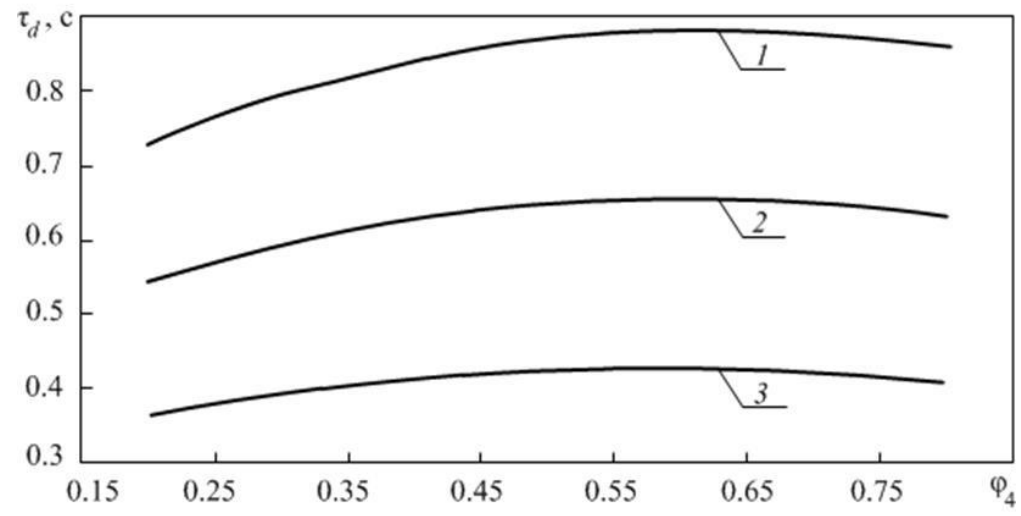

Figure 4. The dependence of the WCF ignition delay on weight fraction of coal component for particles with different initial diameter [34]: $1-\mathrm{d}=0.8 \cdot 10^{-3} \mathrm{~m} ; 2-\mathrm{d}=0.6 \cdot 10^{-3} \mathrm{~m} ; 3-\mathrm{d}=0.4 \cdot 10^{-3} \mathrm{~m}$.

Regarding to fig. 4 , the values of $\tau_{\mathrm{d}}$ grows with $\varphi_{4}$ up to $\varphi_{4}=0.55-0.65$. Further growth of the coal fraction leads to relatively small decrease of the ignition delay (approx. 5-10\%). These dependencies 
[34] caused by changes of effective thermal conductivity of WCF (that is defined by ratio of water and coal in the fuel composition). The thermal conductivity of water is essentially less than this parameter of the coal component. As result, in presence of high water fraction the warming of the thin subsurface layer of the water-coal fuel up to the boiling temperature occurs faster than in case of the uniform coal mass. A little decrease of $\tau_{\mathrm{d}}$ values (5-6\%) at water content mass fraction less than 0.3 caused by decrease of the heat consumption for phase transitions (evaporation of water) [34]. It is evident that influence of component ratio (solid/liquid) inside the droplet of the WCF on the ignition delay goes down. It is additionally shown [34] that growth of external medium temperature leads to decrease of the influence of the solid phase mass fraction value onto inertia of the ignition.

One of the first set of the investigation results about influence of the slurry humidity on the beginning stages of the heating and evaporation of water-coal fuel droplets were present at [35]. The experimental setup for investigations of combustion of the WCF droplet [35] was a metallic sphere with four co-orthogonally oriented holes with glass windows that allows monitoring of the ignition process. The high speed video recording of the observed processes was done. The droplet was suspended on the platinum thermocouple ring and introduced into the oven chamber. The thermocouple was measuring the temperature of droplet surface. The second one thermocouple was installed in the middle of the ring to measure the temperature inside the droplet. The temperature of the air (oxidant) in [35] was like $870-1270 \mathrm{~K}$. The observed slurries with working humidity from $45 \%$ to $80 \%$ were made from coal types "G", "D", "OS", "A" and droplets diameter was from $1 \mathrm{~mm}$ to $3.5 \mathrm{~mm}$. It was shown in [35] that process of heat release without visual observation of combustion (2 stage) was started before the finish of water evaporation (1 stage). The droplet was dark but its temperature was growing with growth of the volume for the costs of strong evaporation and exiting of gases [35]. The fuel mixture that appeared near the surface of the droplet after the water evaporation and thermal destruction of the organic part of coal was ignited at the end of the second stage. The third stage was heterogenic ignition and combustion of the carbon and gas-phase combustion of the volatiles. These stages are preliminary before final burning of the chark residue which occurs much faster [35] due to formation of the well-developed reactive surface.

Fig. 5 shows the influence of slurries humidity on the time of the initial droplet evaporation and on the duration of the second stage (the thermal emission without visual observation of combustion process).

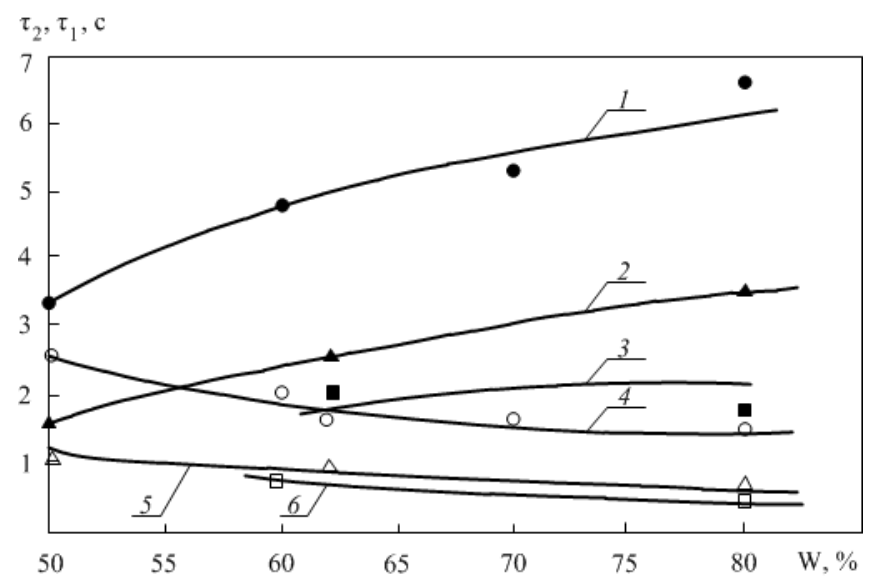

Figure 5. The influence of the slurries humidity [35] on the evaporation time $\tau_{1}$ and onto the duration of the second stage $\tau_{2}: 1-\tau_{1}$ at the $\mathrm{T}=1070 \mathrm{~K} ; 2-\tau_{1}$ at the $\mathrm{T}=1170 \mathrm{~K} ; 3-\tau_{1}$ at the $\mathrm{T}=1270 \mathrm{~K} ; 4-\tau_{2}$ at the $\mathrm{T}=1070$ $\mathrm{K} ; 5-\tau_{2}$ at the $\mathrm{T}=1170 \mathrm{~K} ; 6-\tau_{2}$ at the $\mathrm{T}=1270 \mathrm{~K}$.

The full duration of the first two stages of the process is growing with humidity because the duration of the first stage (that is definitive in time scales) grows with humidity stronger than it decreases at the second stage. The intensity of the combustion is growing with humidity of the fuel 
[35]. It occurs due to well-developed reactive surface of the chark residue that appears at the process of water evaporation from the fuel droplet.

The emphasized results allows us to make conclusion that ignition delay grows non-linearly with water mass fraction of the WCF and the reactivity of the fuel grows too (with decrease of the ignition temperature and increase of the fuel combustion speed).

\subsection{Conditions and parameters of ignition of the water-coal fuel droplets based on different types of coals}

Thermal physical and chemical characteristics of different types of the coal that usually used for water-coal fuel preparation can be enough different [29]. This fact has direct influence on the integral characteristics of ignition and combustion of the WCF droplets. Typical images of the water-coal droplets based on different types of a coal are shown at fig. 6a. The well-developed inner surface of the lignite gives very good possibility to fill pores by water more or less uniformly and to realize more uniform structure of the fuel relatively to coals with higher level of metamorphism. The investigations of the main properties of coals that has influence on ignition and combustion of the WCF are presented at [29]. The fig. $6 \mathrm{~b}$ shows changes of the temperature during ignition and combustion of the WCF droplet [29] that was prepared on different types of coals (lignite, coal and the anthracite) with mass fraction of water near $35 \%$. One can see the exponential growth of the temperature (fig. $6 \mathrm{~b}$ ) that is typical for fuel ignition after the water evaporation. The much higher temperatures and the smaller combustion times are typical for slurries based on coals with higher content of volatiles.
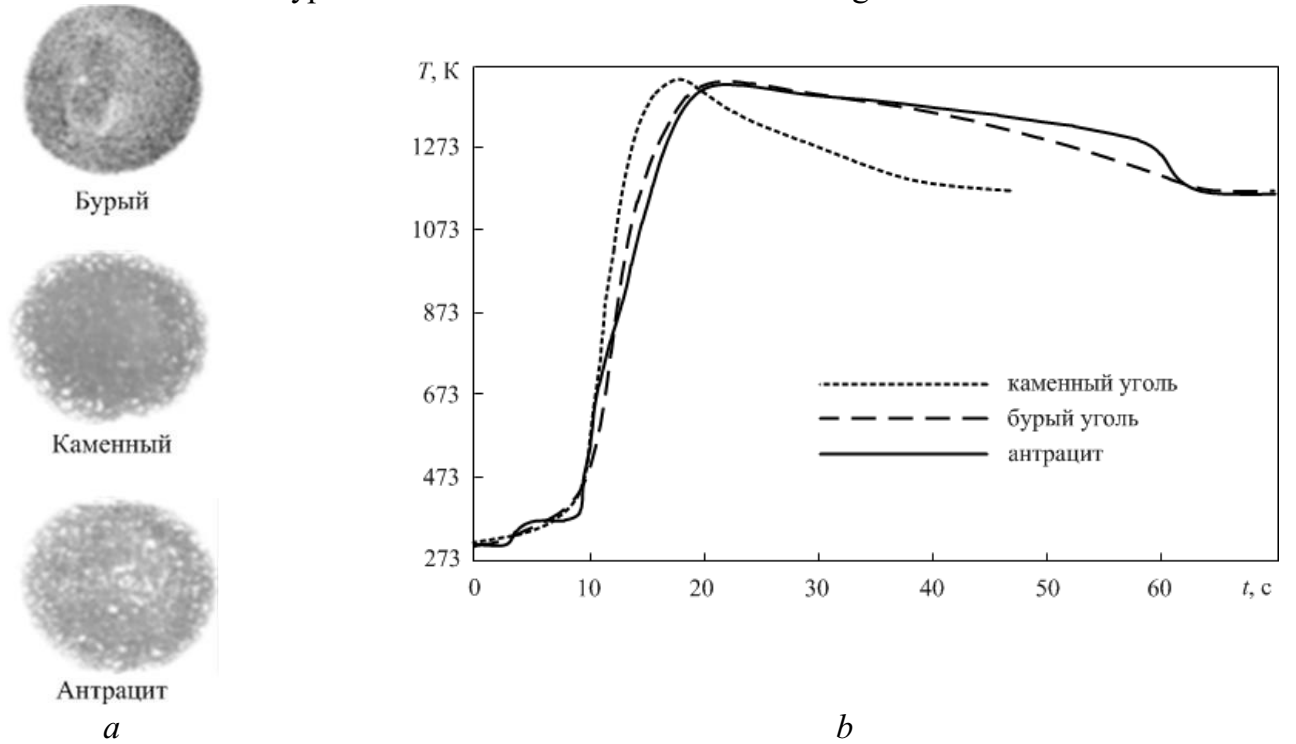

Figure 6. The images of the WCF droplets (a) based on lignite, coal and anthracite particles (the average sizes are 26, 25 and $31 \mathrm{mkm}$ correspondingly). The changes of the WCF temperature (b) at the processes of ignition and combustion for all three types of coal [29].

The results of calculations about definition of the ignition delays of different types of water-coal fuels are presented in [34]. The described WCF were based on coals type ASH (Donetsk coal region), type "D" (Kuznetsk coal region) and lignite type "B2" (Berezovsk deposit area). The main results of the numerical investigations [34] are presented at fig. 7.

It is worth to note, that shorter ignition delays are typical for WCF particles based on lignite (fig. 7). It occurs due to higher reactivity of the lignite (it has higher content of volatiles) and due to low thermal conductivity of it. The water-anthracite particles has slowest ignition. The increase of the oxidant temperature leads to decrease of the differences of ignition delays for the WCF based on different types of coals (fig. 7). 


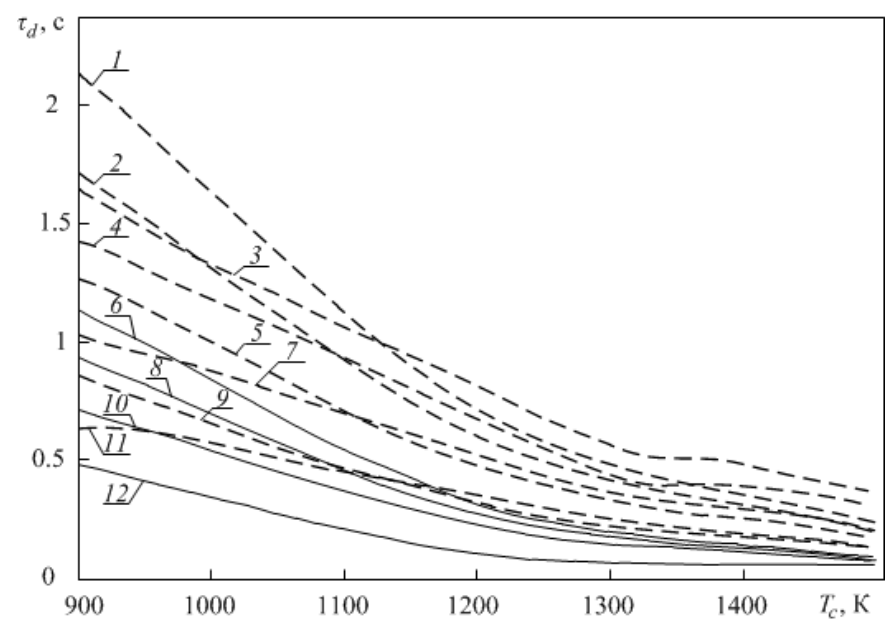

Figure 7. The dependence of the ignition delay of the WCF on the temperature of oxidant for different types of coals with different particle sizes [34]: $1,3,6-1 \cdot 10^{-3} \mathrm{~m} ; 2,4,8-0.8 \cdot 10^{-3} \mathrm{~m} ; 5,7,10-0.6 \cdot 10^{-3} \mathrm{~m} ; 9,11,12-$ $0.4 \cdot 10^{-3} \mathrm{~m}(1,2,5,9$ - type "ASH"; 3, 4, 7, 11 - coal type "D"; 6, 8, 10, 12 - coal type "B2").

Using the results of [29-34], one can make conclusion that from the point of the lower inertia of ignition the most suitable coal components for WCF are those with lower level of metamorphism, higher content of volatiles and lower thermal conductivity.

\subsection{The influence of the coal particle size onto parameters of ignition and combustion of the WCF.}

The fig. 8 shows images of fuel slurry based on lignite with $50 \%$ of water for different coal particle sizes $(26 \mathrm{mkm}, 359 \mathrm{mkm})$ and for their 50/50 mix [29]. The decrease of sizes of the coal particles leads to growth of specific surface of the solid phase relatively to the slurry volume. Also the decrease of slurry particle size leads to growth of the viscosity of the slurry. The irregularity of solid phase distribution occurs after addition of the bigger coal particles to the slurry of small particles. The "empty" space appears in this case inside the droplet (see fig. 8c), that can be interpreted as presence of pores or cavities.

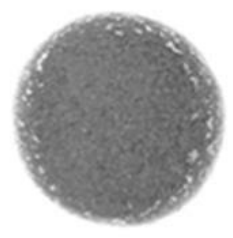

$a$

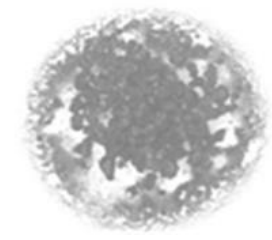

$b$

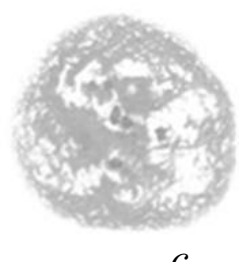

$c$

Figure 8. The images of the WCF droplets [29] based on lignite (50\% of water) with different coal particle sizes: $26 \mathrm{mkm}$ (a), $359 \mathrm{mkm}$ (b) and 50/50 mix (c) of $26 \mathrm{mkm}$ and $359 \mathrm{mkm}$.

The influence of sizes of coal particles used for preparation of the WCF on the combustion time of volatiles and following chark residue agglomerate was shown at [36]. There were analyzed the coal particles with average size $4 \mathrm{mkm}$ and $40 \mathrm{mkm}$, and also the soot particles with $0.045 \mathrm{mkm}$ size. Characteristic sizes of the analyzed water-coal droplets were $200-500 \mathrm{mkm}$. The experiments were done in flow reactor. The temperature inside the chamber during the investigations of the volatiles exiting and combustion of the agglomerate was $1450 \mathrm{~K}$. It was shown that combustion time of two 
WCF droplets with the same sizes (prepared using $4 \mathrm{mkm}$ or $40 \mathrm{mkm}$ coal particles) grows from $20 \mathrm{~ms}$ to $120 \mathrm{~ms}$ with droplet size growth from $200 \mathrm{mkm}$ to $500 \mathrm{mkm}$. The temperature of the droplet during the combustion of the volatiles was exceeding ambient air temperature in chamber for $1000 \mathrm{~K}$ (fig. 9). The temperature and the combustion time of the chark residue (fig. 10) immediately depends on initial size of the WCF droplet. The influence of the coal fineness onto the chark residue combustion is very low [36]. The combustion of the agglomerate with $40 \mathrm{mkm}$ particle size is evidently faster.
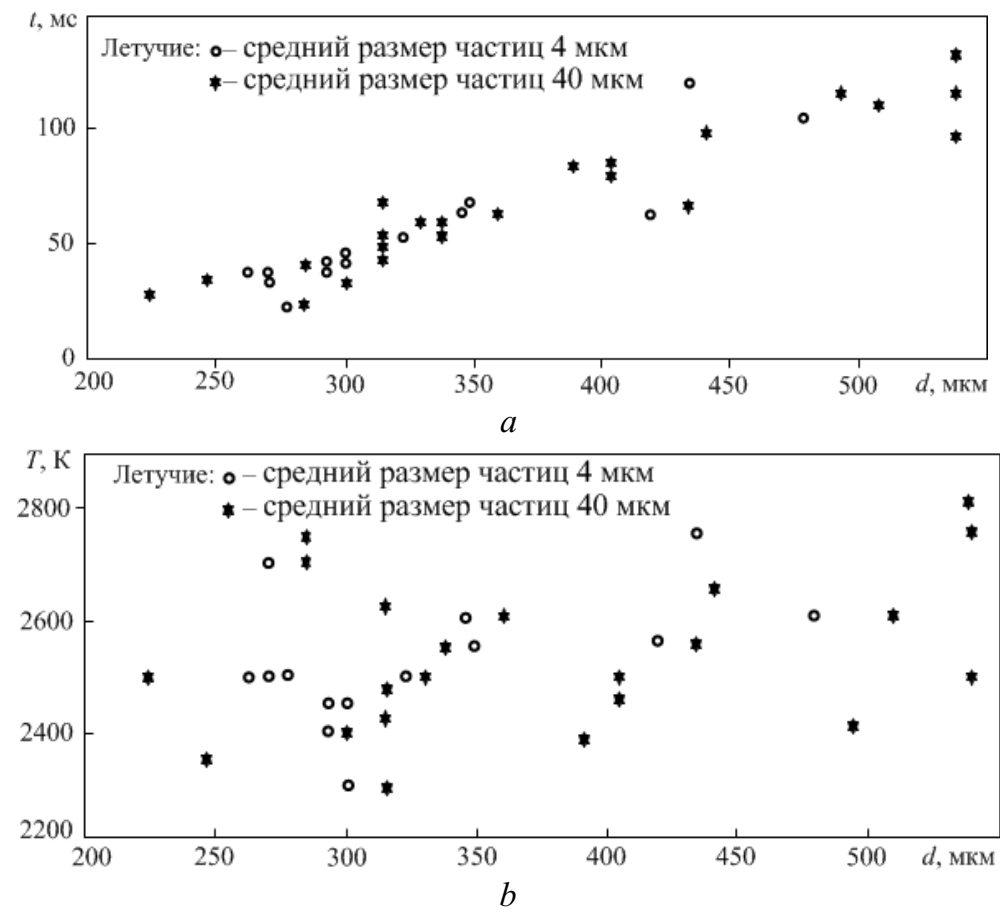

Figure 9. The combustion time of the volatile components for different sizes of the WCF droplet, when the coal particle sizes are $4 \mathrm{mkm}$ and $40 \mathrm{mkm}$ (a). The temperature dependence of the fuel droplet on droplet size for the same coal particle sizes [36].

The combustion of the agglomerate that produced from WCF with different coal fineness was investigated in [37-39]. It was shown that decrease of the particle sizes in agglomerate does not lead to essential growth of the combustion speed as one can preliminary assume.

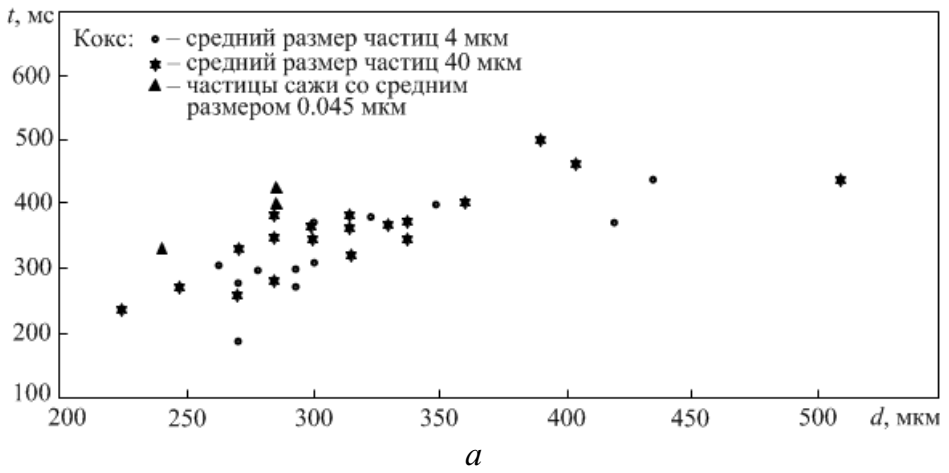




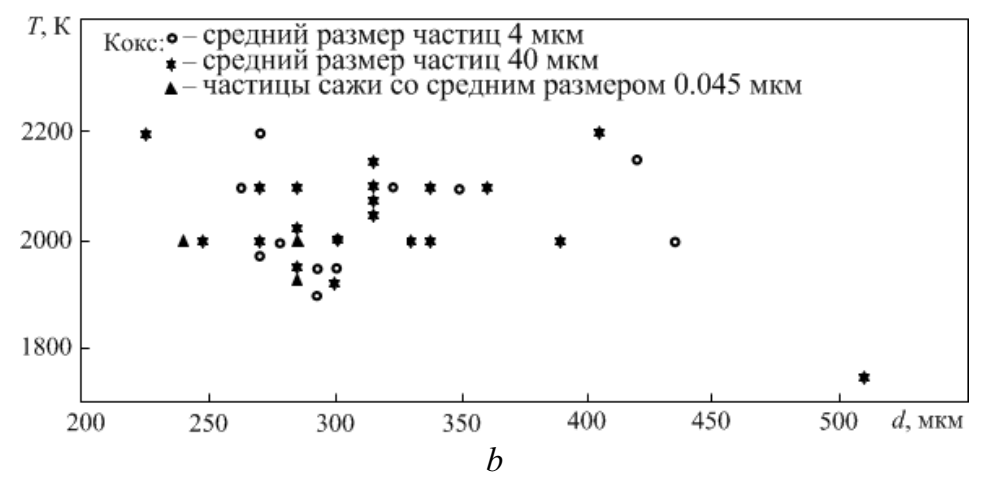

Figure 10. The combustion time of the chark residue for different droplet sizes. The coal particle sizes are 0.045 $\mathrm{mkm}, 4 \mathrm{mkm}$ and $40 \mathrm{mkm}$ (a). The temperature of the chark residue (b) for the different droplet sizes [36].

The influence of both the fineness degree and the changes of inner structure of the coal particles on reactivity characteristics of the WCF were investigated at [40]. The synchronous thermal analysis was used (TGA) [40]. Three types of coals from different Chinese deposit places were analyzed. The main feature of this investigation [40] is that coal dust processing was up to micrometric scale sizes by usage of the planetary mill with different processing times $(4,8,32$ hours). The specific reactive surface of coal matter was essentially increased here. As shown at [41, 42], the milling of the coal by mills with intensive mechanical effect can lead to essential changes of the properties of coal. These are transformation of the porous structure, appearance of solvable products and volatiles, appearance of strong electrical fields, the emission of an electrons or free radicals, creation of new active surfaces, chemical transformations with destructions of some bounds of organic matter of the coal and changes of molecular weight distribution. Changes of the structure of matter under the mechanical processing leads to growth of reactivity of coals [40-42]. The usage of such coals for preparation of the WCF can give us the growth of the WCF reactivity.

The water-coal fuel in [40] was composed from $50 \%$ of coal, $49 \%$ of water and $1 \%$ of plasticizing agent. The main results of [40] are shown at fig. 11.

It is evident that at different heating speeds $(12.5 \mathrm{~K} / \mathrm{min}, 25 \mathrm{~K} / \mathrm{min}$ and $50 \mathrm{~K} / \mathrm{min})$ the ignition temperature of the WCF goes down with decrease of the average size and corresponding growth of specific surface of coal particles (that is related to the typical sizes of pores on the fuel surface). The significant decrease of the activation energy of the WCF was also emphasized due to development of the inner surface of the coal matter.

We can make conclusion that in common case the sizes of particles used for preparation of the water-coal fuel does not has essential influence onto parameters of ignition and combustion processes. The comparison of results for different regimes of modern systems of fuel processing for thermal energetics makes it clear. Thus, the source of raw materials for the WCF preparation is enough large. 

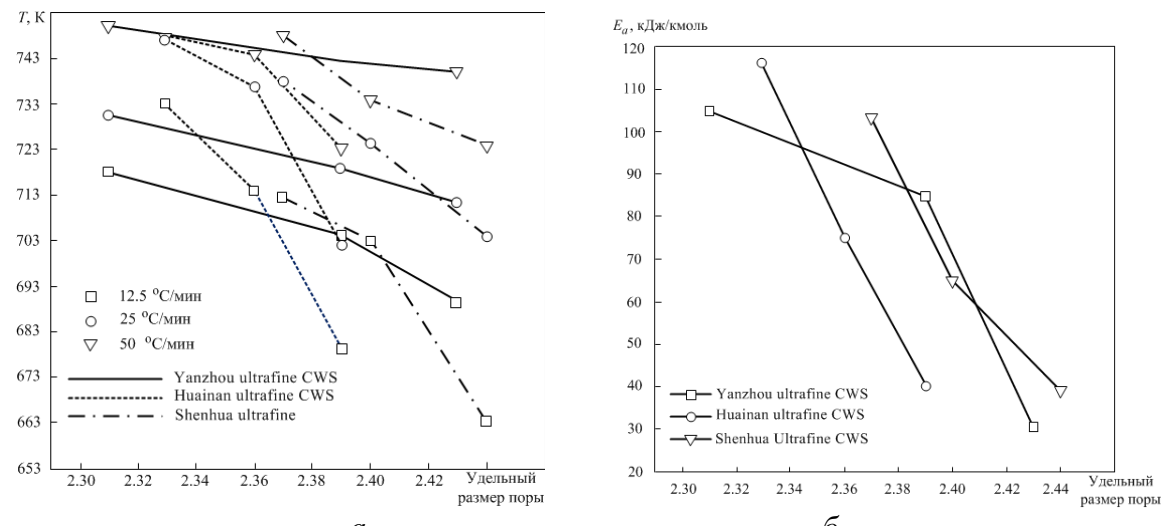

$a$

б

Figure 11. The ignition temperature of three different coals (a) at different speed of heating. Activation energy changes (b) for process of the WCF ignition [40].

\subsection{The atomization of the water-coal fuel}

Special systems of fuel atomization are used inside the oven chambers for intensification of the combustion processes. In contrary to liquid fuels, the decay of the WCF droplets has own features. The decrease of the coal particles sizes inside the WCF droplets can stimulate the droplet decay going to smaller fragments. At another hand, it increases the viscosity of the slurry and therefore make droplet more stable in presence of the external aerodynamic forces. The work [43] shows that average size of the droplets by Sauter (at the end of the secondary droplets decay for finer droplets) is bigger than average droplet size for the WCF decay starting from bigger sizes (fig. 12b). This fact is permanently present even if pressure inside the nozzle was changed (fig. 12b). This effect could be explained [43] by the decrease of the slurry viscosity at particle size growth.
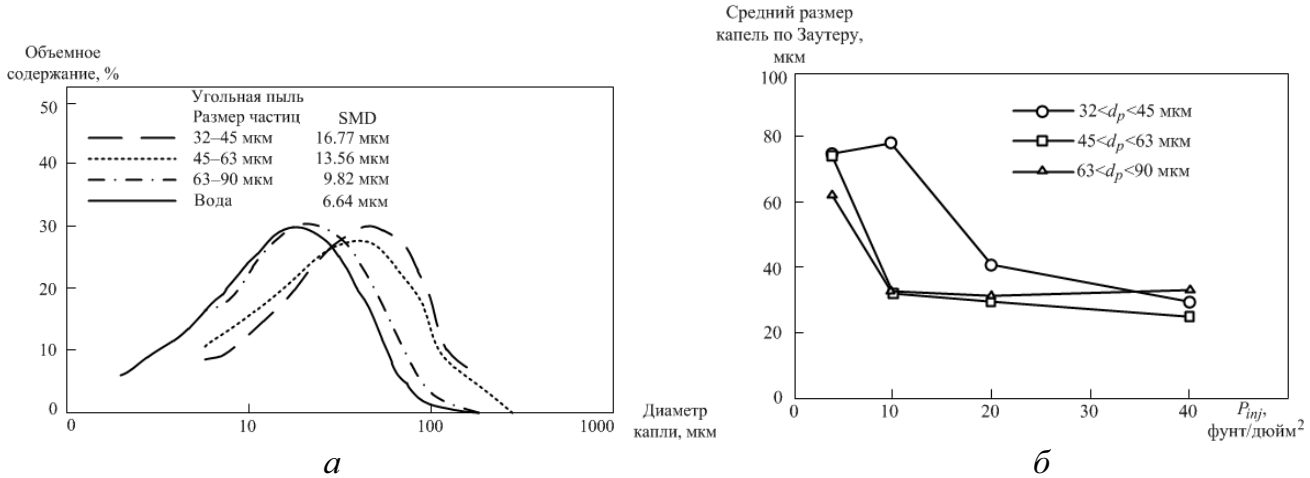

Figure 12. Characteristics of an atomization of the WCF made from coal dust with particle sizes $(32-45 \mathrm{mkm}$, 45-63 $\mathrm{mkm}$ and 63-90 mkm): the size distribution of droplets (a); the dependence (b) of the average droplet size by Sauter (at the secondary WCF decay) on pressure at the nozzle [43].

Similar results were obtained by another authors (for example, $[44,45,46]$ ), where it was proven that the size of the coal particles inside the slurry grows during the secondary decay.

\subsection{Usage of the computational hydrodynamics for optimization of the WCF ignition process inside the technological devices}

The combustion of the atomized water-coal fuel has enough complicated sequence of stages. The fundamental of them are: the decay of the WCF stream inside the combustion chamber for droplets; 
thermal energy exchange of the droplets with ambient medium; exiting and combustion of the volatiles which are products of thermal decomposition of the complicated organic compounds of the fuel; the combustion of the solid residue which is interaction between chark carbon and gas components $\left(\mathrm{O}_{2}, \mathrm{CO}_{2}, \mathrm{H}_{2} \mathrm{O}\right)$ that are diffusing to the droplet surface. Not only fuel parameters has to be taken in account but also external conditions related to chamber design or method of fuel combustion has definitive influence.

One of the fundamental problems during the development of physical and mathematical models for complex investigations of the WCF combustion is choice of an optimal simplifications that allows to obtain enough good correlation between the simulation and experimental data. On the other hand, the simplified approach should operate without excessive deepening into details of physical and chemical processes. Just relatively small set of an appropriate models could be emphasized for nowadays.

For example, the models of non-isothermal and incompressible multi-component gas together with two-parametric model of turbulence were used for description of the WCF droplets combustion in [47-49]. The convective and radiation thermal exchange between the droplet and the environment were taken in account. The splitting of the jet into droplets was not considered. The estimated finite distribution of sizes of the WCF droplets was predefined. The difference of such method from the model of coal particle combustion was in certain difference of activation energies for fuel droplets oxidation.

The simulation of the secondary decay of the WCF droplet was done in [50]. The Large Eddy Simulation method (LES) was used there together with Volume of Fluid (VOF) method for free surface approximation. The non-Newton fluid theory was used to describe the viscosity effects for the water-coal fuel. The comparison of this simulation results with experimental data [51] shows that proposed at [50] approach allows having enough good correlation in case of right choice of the rheological properties of the slurry.

The recent models of conjugated thermal-weight transfer based on non-stationary differential equations for the system "WCF particle - oxidant" (for example, [52-56]) has enough wide set of an assumptions. These assumptions mainly limits the application of the simulation results for sets or jets of particles [52-56] that typically present in the real power units (it appears there due to fuel atomization). Using these models, one can make estimations of integral characteristics of an individual WCF particle ignition (in particular about the ignition delay time, the extreme temperatures etc.). It is also possible to emphasize the dependencies of these parameters (products of combustion, screening surfaces of combustion chamber etc.) on environment temperature and particle size. Additionally these models allows to distinguish the scales of influence of the exothermal effects of water evaporation, thermal decomposition of the organic part of the fuel, chemical interaction of chark carbon and steam. It describes changes of thermo-physical properties of coals with temperature growth or changes of particle shape and finally estimate the effect of all mentioned earlier onto the conditions and parameters of ignition. The mentioned theoretical works [52-56] demonstrates enough good correlation with experimental data. However analysis of the results and their connection with initial data gives the reason for conclusion that corresponding assumptions and simplifications could be enough hard to use for the analysis of the WCF systems.

The big number of conjugated physical and chemical processes, the non-Newton behavior of a slurry and some other features of the WCF droplets combustion requires to build very complicated and non-trivial models. Such task is not solved yet and opens the wide area for future investigations.

\section{Conclusion}

Current analysis of the known approaches to investigation of the ignition and combustion processes for the WCF together with analysis of their results allows to make conclusion about a large groundwork of scientific society in this area of knowledge. The obtained results shows essential 
possibilities regarding to driving of the WCF ignition and, as result, the potential of growth of the efficiency of WCF usage in energetics.

The review was done for the expenses of funds of Russian Science Foundation (project № 15-1910003).

\section{References}

1. G.S. Khodakov, Heat Power Engineering, (1), 35 (2007)

2. $\quad$ L. Chen, Y. Duan, M. Liu, Fuel, 89 (5), 1119 (2010)

3. Z. Yun, G. Wu, X. Meng, Y. Zhang, F. Shi, Y. He, X. Luo, Min. Sci. Technol., 21 (3), 343 (2011)

4. R. Wang, J. Liu, F. Gao, J. Zhou, K. Cen, Fuel Process. Technol.,104, 57 (2012)

5. H. Zhao, H.-F. Liu, J.-L. Xu, W.-F. Li, W. Cheng, Chem. Eng. Sci., 78, 63 (2012)

6. X. Chen, L. Zhao, X. Zhang, C. Qian, Energy Convers. Manage., 62, 70 (2012)

7. H. Zhao, Y.-B. Hou, H.-F. Liu, X.-S. Tian, J.-L. Xu, W.-F. Li, Y. Liu, F.-Y. Wu, J. Zhang, K.-F. Lin, J. Non-Newtonian Fluid Mech., 211, 1 (2014)

8. Y. Tu, Z. Xu, W. Wang, Powder Technol., 281, 121 (2015)

9. Q. He, D. Xie, R. Xu, T. Wang, B. Hu, Fuel, 159, 40 (2015)

10. M. Saito, M. Sadakata, T. Sakai, Fuel, 62 (12), 1481 (1983)

11. H. A. Usui, J. Non-Newtonian Fluid Mech., 60 (2-3), 259 (1995)

12. K. Takeno, K. Tokuda, T. Ichinose, S. Kaneko, Symposium (International) on Combustion, 26, (2), 3223 (1996)

13. H. Takase, S. Miyazaki, Adv. Powder Technol., 10 (4), 427 (1999)

14. K. Aiuchi, R. Moriyama, S. Takeda, S. Kitada, M. Onozaki, Y. Katayama, Fuel Process. Technol., 88 (4), 325 (2007)

15. D. F. Umar, H. Usui, Y. Komoda, Muta'alim, Fuel Process. Technol., 90. (4), 611

16. I.KH. Nekhoroshii,. S. P. Kostovetskii, V.I. Murko, S.Yu. Razzhivin, K.N. Troubetzkoy, Thermal Engineering, 44 (2), 13, (1997)

17. A.P. Burdukov, A.A. Emel'yanov, V.I. Popov, S.N. Tarasenko, Thermal Engineering, 44 (6), 58 (1997)

18. V.R. Vedruchenko, Thermal Engineering, 47 (2), 156 (2000)

19. E.M. Puzyrev, V.I. Murko, V.N. Zvyagin, V.I. Fedyaev, S.A. Brovchenko, D.A. Dzyuba, I.KH. Nekhoroshii, V.N. Agliulin, Thermal Engineering, (2), 69 (2001)

20. V.I. Murko, Solid fuel chemistry, 35 (2), 62 (2001)

21. M.P. Baranova, B.N. Kuznetsov, Solid Fuel Chem., 37 (6), 14 (2003)

22. A.I. Borzov, M.P. Baranova, Solid Fuel Chem., 40 (4), 36 (2006)

23. D.A. Svishchev, A.V. Keiko, Thermal Engineering, 57 (6), 490 (2010)

24. E.G. Gorlov, A.I. Seregin, G.S. Khodakov, Thermal Engineering, 42 (4), 208 (2008)

25. G.R. Mingaleeva, D.V. Ermolaev, O.V. Afanasyeva, S.S.Timofeeva, Thermal Engineering, 59 (6), $446(2012)$

26. V.A. Borodulya, E.K. Buchilko, L.M. Vinogradov, Thermal Engineering, 61 (7), 496 (2014)

27. G.N. Delyagin, Voprosy teorii goreniya vodougol'noj suspenzii v potoke vozduha, (Szhiganie vysokoobvodnennogo topliva v vide vodougol'nyh suspenzij. Sbornik statej. M.: Nauka, 1967)

28. V.I. Babij, V.M. Barabash, A.M. Hidiyatov, V.A. Stepashina, Vosplamenenie i gorenie kapel' vodougol'noj suspenzii (IX Vserossijskij simpozium po goreniyu i vzryvu, CHernogolovka, 1989)

29. A. Kijo-Kleczkowska, Fuel, 90 (2), 865 (2011)

30. V.V. Salomatov, I.V. Kravchenko, Gorenie i plazmohimiya, (3), 178 (2007)

31. Huang, C. Qin, G. Gao, Theoretical analysis on CWM drop combustion history (Proceedings of the Eighth International Symposium on Coal Slurry Fuels Preparation and Utilization, USA, Orlando, 1986)

32. G. E. Liu, C. K. Law, Fuel, 65 (2), 171 (1986) 
33. A.P. Burdukov, E.I. Karpenko, V.I. Popov, V.N. Razvalyayev, V.D.Fedosenko, Combustion, explosion, and shock waves, 32 (4), 62 (1996)

34. S.V. Syrodoj, Termicheskaya podgotovka $i$ zazhiganie chastic vodougol'nogo topliva primenitel'no k topkam kotel'nyh agregatov (Dissertaciya kand. tekhn. nauk. Tomsk, TPU, 2014)

35. G.N. Delyagin, B.N. Smetannikov, Issledovanie processa vosplameneniya kapli vodougol'noj suspenzii (Novye metody szhiganiya tverdyh topliv i voprosy teorii goreniya. Sbornik nauchnyh trudov. M.: Nauka, 1969)

36. .A. Atal, Y.A. Levendis, Combust. Flame, 98 (4), 326 (1994)

37. G.A. Szekely, G.M. Faeth, AIAA Journal, 20 (3), 422 (1982)

38. G.A. Szekely, G.M. Faeth, 19 (1), 1077 (1982)

39. C-P. Mao, G.A. Szekely, Report of National Aeronautics and Space Administration, 3202,1 (1980)

40. J. Cheng, J. Zhou, Y. Li, J. Liu, K. Cen, Fuel,87 (12), 2620 (2008)

41. A.P. Burdukov, V.I. Popov, G.V. Chernova, M.Yu. Chernetskiy, A.A. Dekterev, N.S. Chernetskaya, V.M. Markova, V.N. Churashev, T.S. Yusupov, Thermal Engineering, 60 (12), 889 (2013)

42. A.P. Burdukov, V.I. Popov, T.S. Yusupov, M.Yu. Chernetskiy, K. Hanjalić, Fuel, 122, 103 (2014)

43. S.Y, Son, K.D. Kihm, Atomization and Sprays, 8 (5), 503 (1998)

44. L. Cronin, P. Sojka, A. Lefebvre, SAE Technical Paper, DOI: 10.4271/852086, (1985)

45. Tsai S.C., Knell E.W. Rheology and its effect on atomization of coal-water slurry (Proceedings of the First Annual Pittsburgh Coal Conference, USA, Pittsburgh. 1984)

46. T.U. Yu, S.W. Kang, M.A. Toqan, P.M. Walsh, J.D. Teare, J.M. Beer, A.F. Sarofim, Proceedings of the Eighth International Symposium on Coal Slurry Fuels Preparation and Utilization, Part 1 (USA, Orlando, 1986)

47. Y.A. Levendis, M. Metghalchi, D. Wise, Catalysis of the combustion of carbonaceous particles (synthetic chars and coal) by addition of calcium acetate (Calcium Magnesium Acetate Book, An Emerging Bulk Chemical for Environmental Applications. Amsterdam: Elsevier. 1991)

48. A.I. Cepenok, YU.V. Ovchinnikov, YU.V. Strizhko, S.V. Lucenko, EHnergetik, (7), 45, 2011

49. A.I. Cepenok, F.A. Serant, I.YU. Beloruckij, A.R. Kvrivishvili, O.I. Stavskaya, V.A. Poloskov, V.G. Boyarchenko, P.R. Egorov, Razrabotka i vnedrenie mufelizirovannyh predtopkov dlya snizheniya tekhnicheskogo minimuma pyleugol'nyh kotlov, (VIII Vserossijskaya konferencii s mezhdunarodnym uchastiem "Gorenie tverdogo topliva", 2012)

50. S. Tavangar, S.H. Hashemabadi, A. Saberimoghadam, Fuel Processing Technology, 132, 153 (2015)

51. A.K. Flock, D.R. Guildenbecher, J. Chen, P.E. Sojka, H.J. Bauer, International Journal of Multiphase Flow, 47, 37 (2012)

52. S.V. Syrodoj, V.V. Salomatov, Gorenie i plazmohimiya, 9 (1), 29 (2011)

53. A.V. Savchenko, V.V. Salomatov, A.V. Gil', L.I. Mal'cev, S.V. Syrodoj, Gorenie i plazmohimiya, $10(2), 95$ (2012)

54. S.V. Syrodoj, V.V. Sylomatov, G.V. Kuznecov, Polzunovskij vestnik, (4-3), 28 (2013)

55. S. V. Syrodoy, G. V. Kuznetsov, V. V. Salomatov, Thermal Engineering, 62 (10), 703

56. G.V. Kuznetsov, V.V. Salomatov, S.V. Syrodoy, Combustion, explosion, and shock waves, 51 (4), 400 (2015). 